\title{
Revisit on How Nasal Blockage has an Effect on Eminence of Life: Facts \& Specifics
}

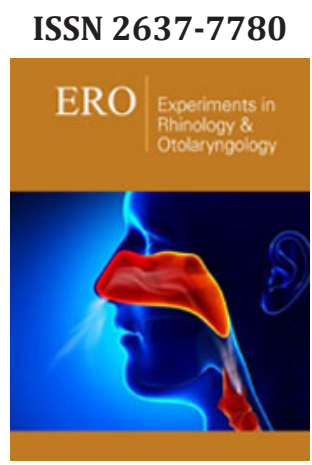

*Corresponding author: Sphoorthi Basavannaiah, Assistant Professor, Department of ENT, Subbaiah Institute of Medical Sciences, Shimoga, Karnataka , India

Submission: 監 May 15, 2020

Published: 眥 May 26, 2020

Volume 3 - Issue 2

How to cite this article: Sphoorthi Basavannaiah. Revisit on How Nasal Blockage has an Effect on Eminence of Life: Facts \& Specifics. Exp Rhinol Otolaryngol 3(2). ERO.000557.2020.

DOI: $10.31031 /$ ERO.2020.03.000557

Copyright@ Sphoorthi Basavannaiah This article is distributed under the terms of the Creative Commons Attribution 4.0 International License, which permits unrestricted use and redistribution provided that the original author and source are credited.

\section{Sphoorthi Basavannaiah*}

Department of ENT, Subbaiah Institute of Medical Sciences, Shimoga, Karnataka, India

\section{Abstract}

Introduction: Nasal breathing distributes roughly 70\% airflow to lungs, but airway obstruction can limit airflow through nose. This limitation of nasal airway obstruction through nose has both mucosal as well as mechanical causes that can significantly compromise the quality of life.

Aims \& Objectives: To find out the commonest cause for nasal obstruction, level of obstruction as well as affection of involvement in Nose \& PNS. This topic is of interest as nasal obstruction, though has a common existence \& prevalence but certain crucial factors that compromise quality of life is still untouched upon in literature.

Methodology: All 626 patients who presented with various causes of nose block were clinically evaluated and suitable management was disposed.

Results: Both Mucosal \& Mechanical groups have their own role in involvement for the basis of nasal obstruction.

Conclusions: DNS \& Developmental origin go hand in hand and is by far occupying nearly $50 \%$ of causes for nasal obstruction, which indirectly suggests that septal correction is mandatory after facial development when symptomatic \& when basics in life are at stake.

Keywords: Nasal blockage; Nasal obstruction; Nasal airway; Airflow; Deviated nasal septum (DNS); Paranasal sinuses(PNS)

\section{Introduction}

Nasal breathing distributes roughly $70 \%$ airflow to lungs, but airway obstruction can limit airflow through nose. While it is a known fact that ear, nose \& throat are interlinked with each other in the form of "triangular immersion". Hence, any cause of nasal block can in a way limit the functioning capacity of the other two systems [1,2]. This limitation of nasal airway obstruction (NAO) through nose has mucosal \&mechanical causes that range from PNS to DNS that can significantly compromise the excellence \& eminence of life leading to un pleasant alarms [3].

\section{Aims \& Objectives}

a) To find out the various causes for nasal obstruction.

b) To look for nasal block based on level of obstruction/any abnormalities of nose \& PNS.

c) To group nasal block causes as per affection of areas in Nose \& PNS.

d) To categorize nasal obstruction according to the aetiology.

e) To classify nasal obstruction as per the symptomatology of presentation.

f) To evaluate disease with relevance to symptom based on gender $\&$ age predisposition of occurrence in terms of ratio.

g) To group the conditions based on their chronicity \& laterality. 


\section{Objective}

It is to bring into light the 3 basic $\&$ vital features that hinder the value of healthy living such as breathe, smell \& sleep as not much about it is mentioned in the literature.

\section{Materials and Methods}

\section{A. Study design: Descriptive study}

B. Place of study: Tertiary Care Hospital, Subbaiah Institute of Medical Sciences, Shimoga.

C. Study period: 1 year (from August 2018 to July 2019).

D. Selection criteria: A random sample of 626 patients (pts) who consulted the ENT outpatient department with nasal obstruction as one of the clinical presentation were assessed \&evaluated clinically, diagnosis was made. Following which, required management algorithm was adapted in all the patients both conservatively as well as surgically.

\section{1) Inclusion criteria}

a) Age group from 5-70 years were considered for the study.

b) All cases of only nasal pathology were considered for the study.

\section{2) Exclusion criteria}

a) Age group of $<5$ years and $>70$ years were excluded from the study.

E. Procedure of the study: Over a period of 1 year, a random sample of $626 \mathrm{pts}$ who consulted ENT OPD with nasal obstruction as one of their main symptom were clinically evaluated after taking a detailed \& thorough history. Following which a probable diagnosis was made. The relevant investigations wherever necessary were done to arrive at a diagnosis.

Management was given based on the diagnosis which was both conservative as well as surgical. They were then followed up for about 6 months. Patients have shown good response to treatment on follow up with symptomatic relief. Informed written consent was taken during the study period. Ethical clearance has been taken from Institutional Ethics Committee before the start of the study.

Results

The observations drawn from the study are depicted both in diagrammatic as well as tabular representation below: (Table 1-4; Figures 1-5)

Table 1: Based on causes for nasal obstruction-----------412+214= 626 .

\begin{tabular}{|c|c|c|c|}
\hline Inferiorturbinate hypertrophy(ITH) & 22 & Tumors/growth/mass of Nose, Nasopharynx \& PNS. & 9 \\
\hline Deviated nasal septum (DNS) & 85 & Vestibulitis/Furunculosis (V/F) & 10 \\
\hline Ethmoidal polyposis (EP) & 31 & Antrochoanal polyp (ACP) & 19 \\
\hline Acute Rhinitis (Ac.R) & 33 & Allergic rhinitisrhinitis(AR) & 44 \\
\hline Septal perforation (SP) & 3 & Atrophic rhinitis (At.R) & 9 \\
\hline Septal haematoma (SH) & 7 & Septal abscess (SA) & 46 \\
\hline Nasal synechiae (NS) & 4 & Adenoid hypertrophy(AH) & 6 \\
\hline Acute Rhinosinusitis (ARS) & 22 & Chronic Rhinosinusitis(CRS) & 4 \\
\hline Cleft lip/palate (CL/CP) & 3 & Cellulitis of face (CF) & \\
\hline Facial trauma including Nasal bone \# (FT) & 16 & DNS with AR & 63 \\
\hline \multicolumn{2}{|c|}{ Combinations (214) } \\
\hline DNS with ITH & 28 & DNS with Migraine & 43 \\
\hline DNS with Rhinosinusitis & 38 & DNS with ITH with sinusitis & 29 \\
\hline
\end{tabular}

Table 2: Of 626pts with nasal pathology, table below shows symptoms accompanying nasal obstruction as Secondary (SS) \& Associated (AS) which is depicted in the tabular presentation below (Table 2, 3 \& 4).

\begin{tabular}{|c|c|c|c|c|c|c|c|c|c|c|}
\hline Nasal Symptoms & ITH (22) & DNS (85) & EP (31) & ACP (19) & Ac.R (33) & At.R (4) & AR (44) & ARS (22) & CRS (35) & NM/NT/R $(9+4)$ \\
\hline Rhinorrhoea & S 7 & A 10 & S 4 & S 4 & S 10 & & S13 & S 5 & S 7 & A 4 \\
\hline Anosmia & A 6 & A 8 & S 5 & S 2 & & S 2 & S 3 & & A 3 & S 3 \\
\hline Headache & S 4 & S 17 & S 6 & S 5 & S 7 & A 1 & S 5 & S 6 & S 9 & A 2 \\
\hline $\begin{array}{l}\text { Mouth breathing/ } \\
\text { Halitosis }\end{array}$ & A 5 & & A 3 & & A 1 & & A 2 & & & \\
\hline Snoring & & S 15 & S 5 & & S 2 & & A 2 & & & S 2 \\
\hline Epistaxis & & S9 & & A 1 & & S 1 & & & & S 2 \\
\hline Aural fullness & & A 4 & & A 1 & & & A 1 & & A 2 & \\
\hline Otorrhoea & & A 4 & A 2 & & & & & & & \\
\hline h/o recurrent URI & & S 14 & & & S 7 & & A 2 & & S 5 & \\
\hline
\end{tabular}




\begin{tabular}{|c|c|c|c|c|c|c|c|}
\hline Voice change & A 4 & A 3 & A 1 & & & & \\
\hline $\begin{array}{l}\text { Hawking } \\
\text { sensation }\end{array}$ & & A 2 & A 2 & & A 3 & S 2 & A 3 \\
\hline $\begin{array}{c}\text { Hearing } \\
\text { disturbances }\end{array}$ & & A 1 & & A 1 & & A 1 & \\
\hline Hemifacial pain & & & S 2 & & & $\mathrm{~S} 2$ & $\mathrm{~S} 4$ \\
\hline $\begin{array}{c}\text { Cheek/Lid } \\
\text { swelling }\end{array}$ & & & A 1 & & & A 2 & A 2 \\
\hline Fever & & & & A 4 & & A 4 & \\
\hline Otalgia & & & & A 1 & A 1 & & \\
\hline $\begin{array}{l}\text { h/o allergic } \\
\text { symptoms }\end{array}$ & & & & & S12 & & \\
\hline
\end{tabular}

\begin{tabular}{|c|c|c|c|}
\hline Rhinorrhoea & $\mathrm{S}(50), \mathrm{A}(14)$ & Anosmia & $\mathrm{S}(13), \mathrm{A}(17)$ \\
\hline Headache & $\mathrm{S}(50), \mathrm{A}(3)$ & Mouth breathing/Halitosis & $\mathrm{A}(11)$ \\
\hline Snoring & $\mathrm{S}(24), \mathrm{A}(2)$ & Epistaxis & $\mathrm{S}(12), \mathrm{A}(1)$ \\
\hline Aural fullness & $\mathrm{A}(8)$ & Otorrhoea & $\mathrm{A}(6)$ \\
\hline h/o recurrent URI & $\mathrm{S}(26), \mathrm{A}(2)$ & Voice change & $\mathrm{A}(3)$ \\
\hline Hawking sensation & $\mathrm{S}(2), \mathrm{A}(10)$ & Cheek/Lid swelling & $\mathrm{A}(3)$ \\
\hline Hemifacial pain & $\mathrm{S}(8)$ & Otalgia & $\mathrm{A}(2)$ \\
\hline Fever & $\mathrm{A}(8)$ & & \\
\hline
\end{tabular}

Table 3: Symptoms accompanying nasal obstruction in various nose pathology.

\begin{tabular}{|c|c|c|c|c|c|c|c|c|c|}
\hline Nasal Symptoms & SH (7) & SA (9) & SP (3) & AH (46) & NS (4) & $\mathrm{V} / \mathrm{F}(\mathbf{1 0})$ & $\mathrm{CL} / \mathrm{P}(3)$ & FT (16) & CF (6) \\
\hline Fever & A 2 & S 3 & & & & S 4 & & & S 3 \\
\hline Epistaxis & A 2 & A 2 & A 1 & & & A 2 & & S 6 & \\
\hline Rhinorrhoea & S 2 & A 2 & & S 8 & S 2 & S 3 & & & \\
\hline Anosmia & S 1 & S 2 & S 2 & & & & & & \\
\hline $\mathrm{h} / \mathrm{o}$ recurrent URI & & & & S 13 & & & & & \\
\hline Hawking sensation & & & & S 10 & & & & & \\
\hline Headache & & & & A 4 & A 2 & A 1 & & & A 1 \\
\hline Mouth breathing/Halitosis & & & & A 11 & & & & & \\
\hline Nasal regurgitation & & & & & & & S 2 & & \\
\hline Voice change & & & & & & & A 1 & & \\
\hline $\mathrm{h} / \mathrm{o}$ trauma & & & & & & & & S 7 & \\
\hline Cheek/Lid swelling & & & & & & & & A 3 & S 2 \\
\hline Fever & & \multicolumn{3}{|c|}{$S(10), A(2)$} & \multicolumn{2}{|c|}{ Epistaxis } & & \multicolumn{2}{|c|}{$S(6), A(7)$} \\
\hline Rhinorrhoea & & \multicolumn{3}{|c|}{$S(15), A(2)$} & \multicolumn{2}{|c|}{ Anosmia } & & \multicolumn{2}{|c|}{$\mathrm{S}(5)$} \\
\hline $\mathrm{h} / \mathrm{o}$ recurrent URI & & \multicolumn{3}{|c|}{$S(13)$} & \multicolumn{3}{|c|}{ Hawking sensation } & \multicolumn{2}{|c|}{$\mathrm{S}(10)$} \\
\hline Headache & & \multicolumn{3}{|c|}{$\mathrm{A}(8)$} & \multicolumn{3}{|c|}{ Mouth breathing/Halitosis } & \multicolumn{2}{|c|}{$\mathrm{A}(11)$} \\
\hline Nasal regurgitation & & \multicolumn{3}{|c|}{$\mathrm{S}(2)$} & \multicolumn{3}{|c|}{ Voice change } & \multicolumn{2}{|c|}{$\mathrm{A}(1)$} \\
\hline $\mathrm{h} / \mathrm{o}$ trauma & & \multicolumn{3}{|c|}{$S(7)$} & \multicolumn{2}{|c|}{ Cheek/Lid swelling } & & \multicolumn{2}{|c|}{$S(2), A(3)$} \\
\hline
\end{tabular}

Table 4: Symptoms accompanying nasal obstruction in various nose pathology.

\begin{tabular}{|c|c|c|c|c|c|c|}
\hline Nasal Symptoms & DNS with ITH (28) & DNS with RS (38) & DNS with AR (63) & $\begin{array}{c}\text { DNS with } \\
\text { Migraine (43) }\end{array}$ & $\begin{array}{c}\text { DNS with ITH with } \\
\text { Sinusitis (29) }\end{array}$ & $\begin{array}{c}\text { DNS with External } \\
\text { Deformity (13) }\end{array}$ \\
\hline Rhinorrhoea & S 6 & S 5 & S 13 & S 14 & S 9 & S 4 \\
\hline h/o recurrent URI & S 8 & S 6 & & & S 4 & \\
\hline Anosmia & A 3 & S 4 & & & & \\
\hline Snoring & A 3 & & & A 3 & S 2 & A 1 \\
\hline
\end{tabular}




\begin{tabular}{|c|c|c|c|c|c|c|}
\hline Headache & S 5 & S 9 & S 11 & S 11 & & A 1 \\
\hline $\begin{array}{c}\text { Hearing } \\
\text { disturbances }\end{array}$ & A 3 & A 2 & A 3 & & A 2 & \\
\hline Voice change & & A 2 & & & A 2 & \\
\hline Hemifacial pain & & A 4 & & & S 4 & \\
\hline Otorrhoea & & A 2 & & & & \\
\hline Hawking sensation & & A 4 & A 9 & & A 2 & \\
\hline $\begin{array}{l}\text { h/o allergic } \\
\text { symptoms }\end{array}$ & & & S 21 & & & \\
\hline Otalgia & & & A 3 & & & \\
\hline Aural fullness & & & A 3 & & A 2 & \\
\hline $\begin{array}{l}\text { Migrainous } \\
\text { symptoms }\end{array}$ & & & & A 15 & & \\
\hline $\begin{array}{l}\text { Mouth breathing/ } \\
\text { Halitosis }\end{array}$ & & & & & A 2 & \\
\hline h/o trauma & & & & & & S 4 \\
\hline Epistaxis & & & & & & S 3 \\
\hline
\end{tabular}

\begin{tabular}{|c|c|c|c|}
\hline Rhinorrhoea & $\mathrm{S}(51)$ & h/o recurrent URI & $\mathrm{S}(18)$ \\
\hline Anosmia & $\mathrm{S}(4), \mathrm{A}(3)$ & Snoring & $\mathrm{S}(2), \mathrm{A}(7)$ \\
\hline Headache & $\mathrm{S}(36), \mathrm{A}(1)$ & Hearing disturbances & $\mathrm{A}(10)$ \\
\hline Voice change & $\mathrm{A}(4)$ & Hemifacial pain & $\mathrm{S}(4), \mathrm{A}(4)$ \\
\hline Otorrhoea & $\mathrm{A}(2)$ & Otalgia & $\mathrm{A}(3)$ \\
\hline h/o allergic symptoms & $\mathrm{S}(21)$ & Migrainous symptoms & $\mathrm{A}(15)$ \\
\hline Aural fullness & $\mathrm{A}(5)$ & h/o trauma & $\mathrm{S}(4)$ \\
\hline Mouth breathing/Halitosis & $\mathrm{A}(2)$ & & \\
\hline
\end{tabular}

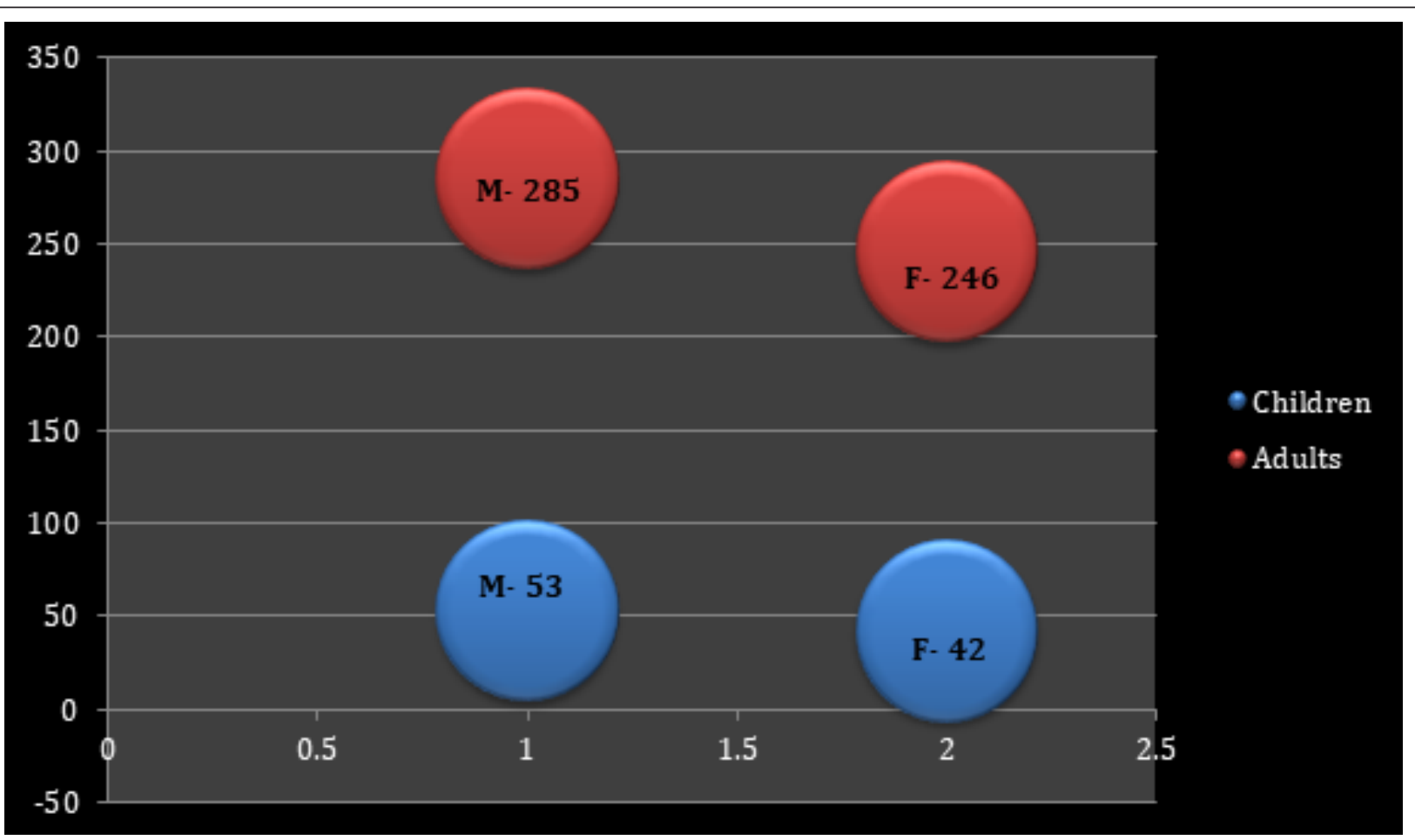

Figure 1: Bubble representation showing the total population in terms of gender $\&$ age included in the study. The percentage distribution among them is 95 children (15\%) \& 531 adults $(85 \%)$ while 338 males (54\%) \& 288 females (46\%). 

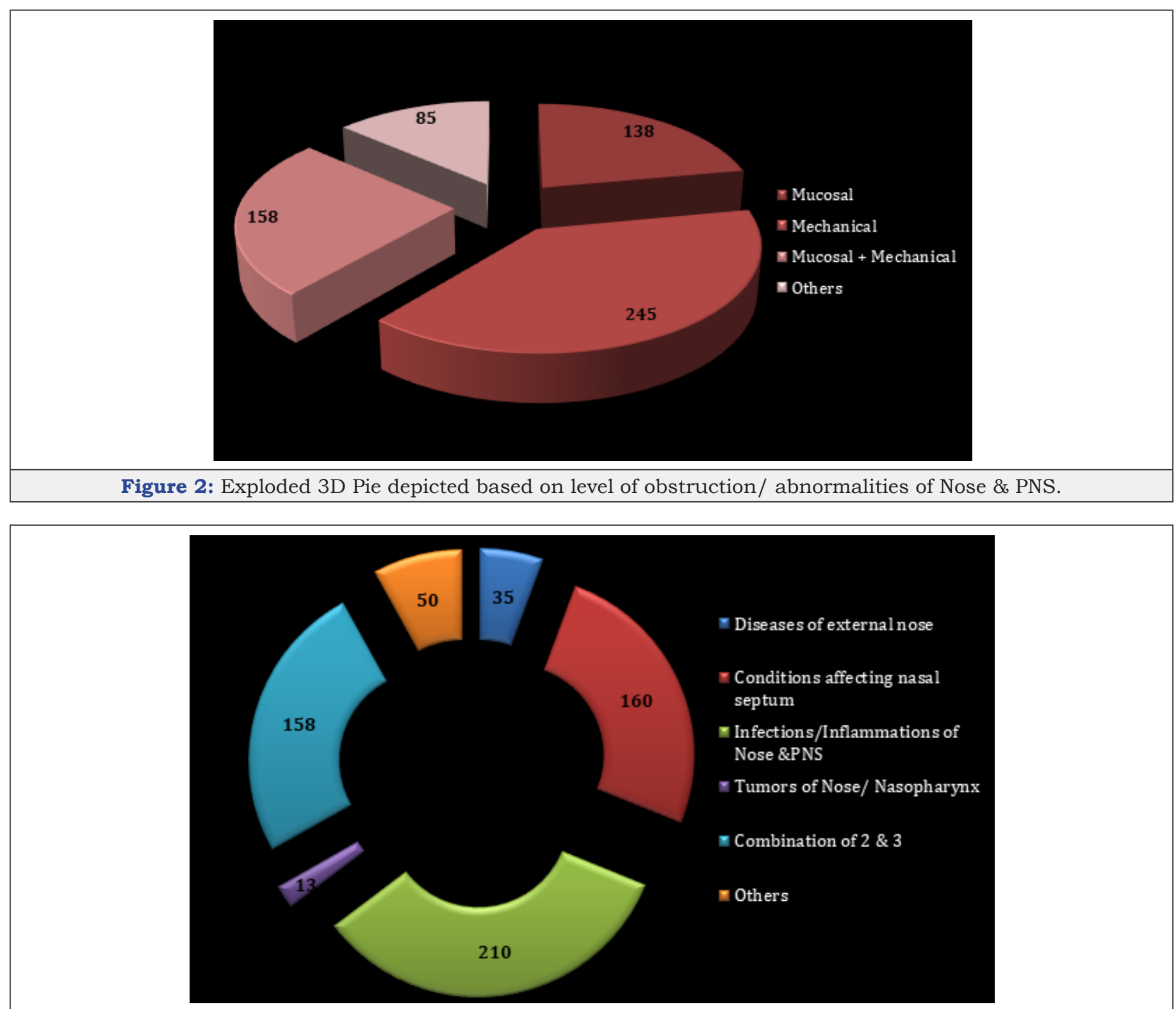

Figure 3: Exploded doughnut diagram showing affection of areas in Nose \& PNS with causes of nasal obstruction.

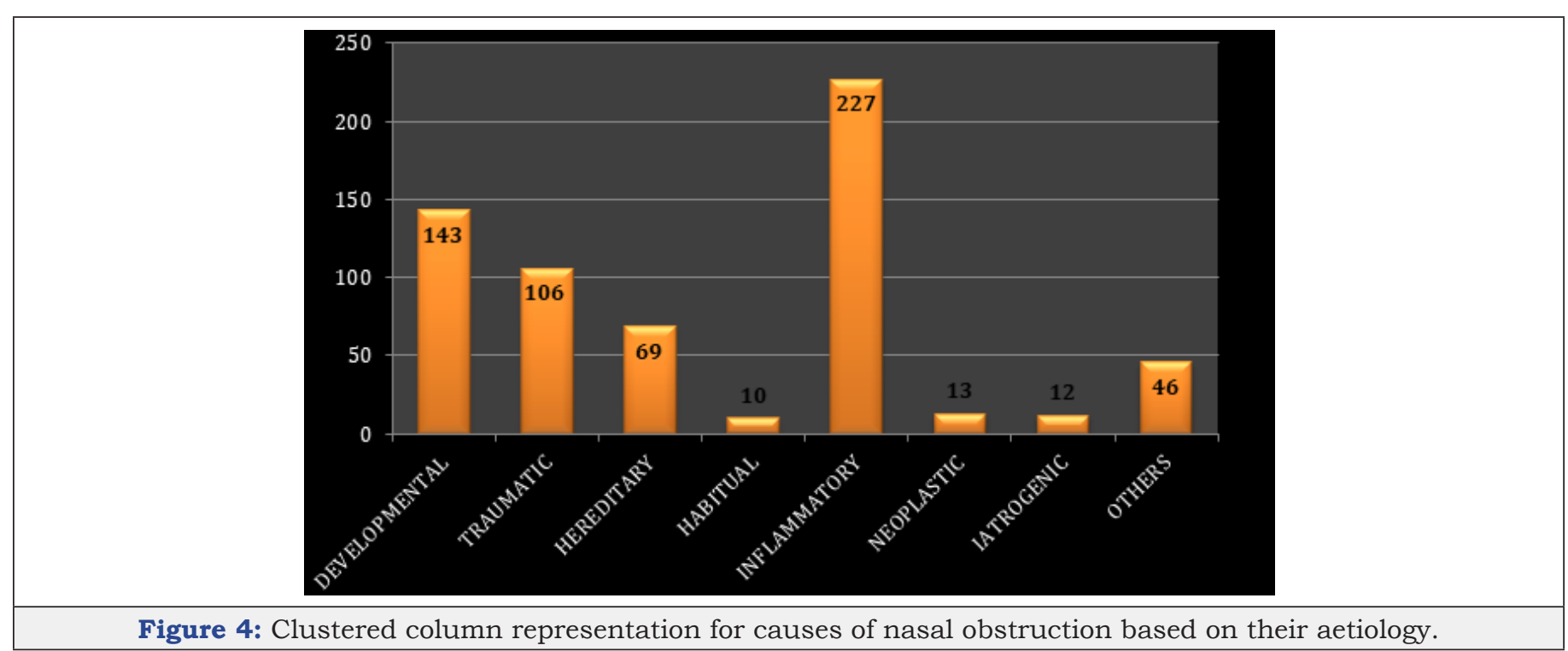




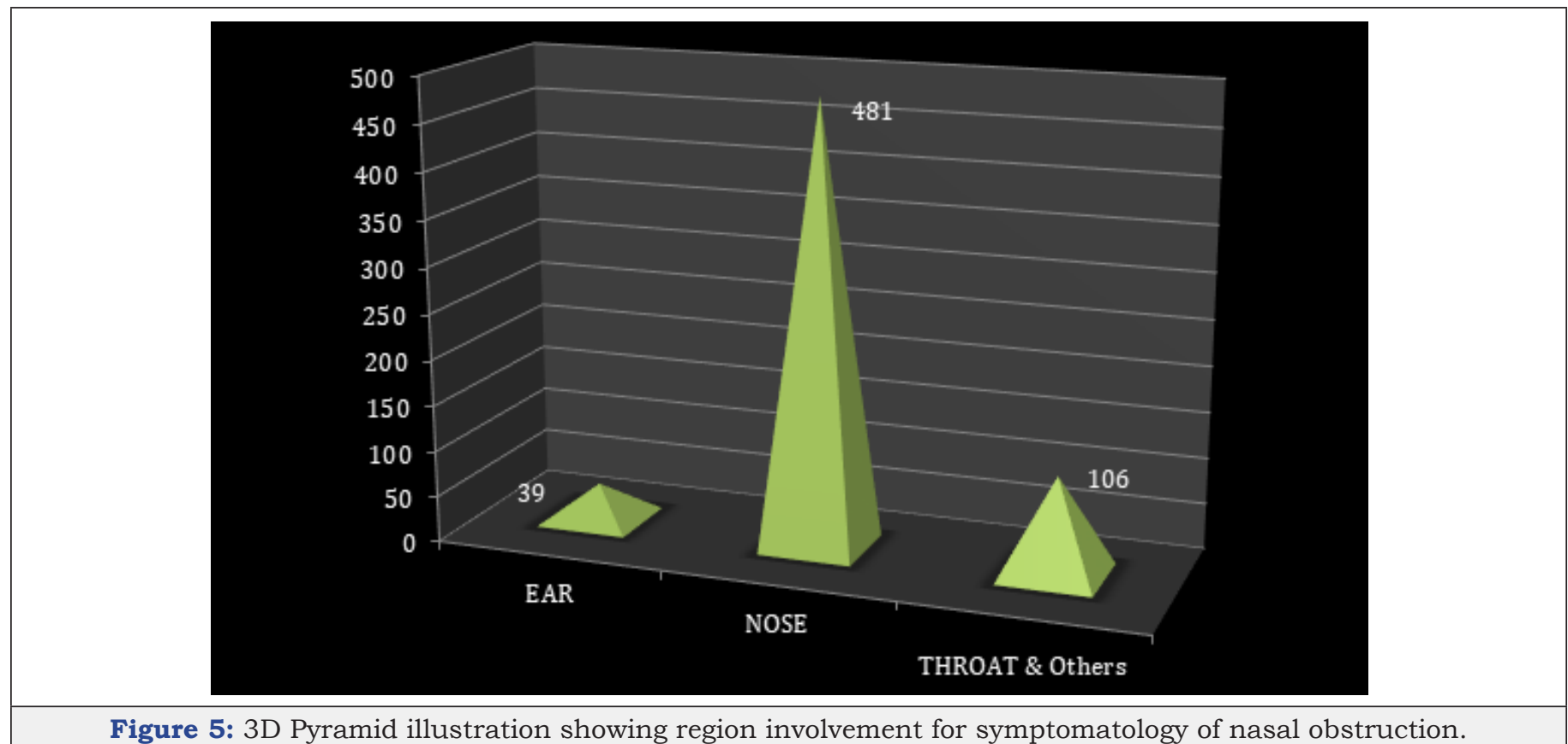

\section{Discussion}

Nasal congestion is the most common symptom for both mucosal \& mechanical cause in nose \& PNS region. Congestion, due to physical obstruction of nasal passages as a result of structural variations \&/or modulation of sensory perception. Mucosal inflammation has precise and solid factors that contribute to nasal congestion $[4,5]$. Biologically active agents \& cell types (eg, histamine, TNF- $\alpha$, IL's, cell adhesion molecules) contribute to inflammation, that manifest as raised nasal secretions, venous engorgement \&tissue oedema. This can possibly cause impaired airflow \& feeling of nasal congestion [6,7]. Altered sensory perception \& subjective sense of congestion are due to inflammation-induced changes in sensory afferents which innervate nose through expression of peptides \& receptors $[8,9]$.

Nasal congestion has many causes that range from a mild irritation to lethal condition. The various sources for nasal block can cause headache to halitosis due to inflammatory to iatrogenic pathology\& developmental to dangerous concern [10,11]. Various origins range from simple coryza to complex concha bullosa, narrow nasal valve to wide cleft palate as well as upper airway resistance syndrome to empty nose syndrome all of which can lead to nasal obstruction. As it known that face has a rich blood supply, specifically nose which has the most constricted and confined vessels and (danger area of face). Hence, any neglected conditions can lead to severity in the form of cavernous sinus thrombosis etc, jeopardising life $[12,13]$.

Most people are referred to as "obligate nasal breathers". During first few months of life, nasal congestion in an infant can interfere with breastfeeding causing respiratory distress while in older children \& adolescents it can just be bothersome with certain difficulties. Nasal congestion can interfere with hearing and speech $[14,15]$. Significant congestion mainly in adults and sometimes in children even may interfere with sleep cause snoring with mouth breathing that can be associated with sleep apnoea or upper airway resistance syndrome [16-18]. While in children, nasal congestion from adenoid hypertrophy has caused chronic sleep apnoea with insufficient levels of oxygen causing hypoxia as well as right-sided heart failure. This problem can be resolved with knocking out both tonsils \& adenoids. However, this problem often relapses later in life due to craniofacial alterations from chronic nasal congestion $[19,20]$.

Hence, any cause of nasal obstruction must evaluate thoroughly. After which proper treatment modality has to be administered \& followed either conservative line as in Antibiotics, Nasal decongestants either topical \& oral, Antihistamines with +/Analgesics. Surgical line of treatment $[21,22]$ as per requirement is Septoplasty + /-Submucous resection, Partial inferior turbinectomy \& Functional Endoscopic sinus surgery (FESS). The same protocol was followed in our case too. After a Diagnostic nasal endoscopy \& CT PNS, appropriate treatment measures were adapted [2325]. Total 626pts were considered for the study. Pts presented with various nasal pathology comprising of 26 conditions (with 20 single causes \& rest 6 with combined causes). They presented with nasal obstruction as their Primary Symptom (PS) over a study period of 1 year and were followed over for 6 months now. Nasal obstruction has been categorically dissected into various groups which are individually elaborated in the matter mentioned below.

Out of 26 causes for nasal obstruction that were presented at the OPD, 412pts (66\%) belonged to single causes while $214 \mathrm{pts}$ (34\%) belonged to combined causes for nasal obstruction. The top 5 causes for nasal obstruction are DNS-85pts, Rhinitis-81pts, DNS with AR-63pts, Rhinosinusitis-57pts \& Nasal polyposis- 50pts. While it is mostly combined causes with DNS which form the bulk of pts, that totals up to $(214+85=299 \mathrm{pts})(48 \%)$. This data in the study here shows that nearly $50 \%$ of causes fall under Mechanical group which is superior to Mucosal cause for nasal obstruction that is DNS. 
As per age \& sex distribution in this study, 95pts were children (C) \& 531pts were adults (A) and their ratio of C:A is nearly 1:6. While 338pts were males (M) \& 288pts were females (F) and their ratio of M:F is nearly 1:2. This data in the study here tells us that there is wide gap difference between Children \& Adults while that is not so in Males \& Females.

In this study with reference to the chroni city of conditions, 126pts (20\%) had Acute (A) causes for nasal obstruction while rest 500 pts $(80 \%)$ had Chronic (C) causes. Hence the ratio of A:C is $1: 4$. This data in the study refers to the fact that acute cases are far less in occurrence compared to chronic. Hence, mostly conservative management is by far proven sufficient and also pts have become more aware\& alert to get medical help at the earliest. But considering the laterality of involvement in terms of causes for nasal obstruction, 145pts (23\%) had Unilateral (U/L) involvement while rest 481pts (77\%) had Bilateral (B/L) involvement. B/L involvement specifies the need for immediate surgical management and also postulates the importance to have a good quality of life in terms of breathe, smell \& sleep as a part of healthy lifestyle. Hence, the ratio of $\mathrm{U} / \mathrm{L}: \mathrm{B} / \mathrm{L}$ is nearly $1: 4$. There is no particular preference or any relevance to the side of involvement either Right or Left side of the nose for nasal obstruction in this study.

As per the level of obstruction with reference to nasal causes, they were categorised into 4 groups: Mucosal-138pts (22\%), Mechanical- 245pts, Combined Mucosal+Mechanical-138pts (25\%) \& Others-85 pts (14\%). In this category, Mechanical causes for nasal obstruction topped the list with $39 \%$ involvement most commonly encountered in this study. As Mucosal causes mainly involves compromising the Osteomeatal complex (OMC) which is Rhinitis \& Rhinosinusistis while Mechanical causes is purely Anatomical constraints that include DNS, ITH, Any mass/growth/polyps etc.

Among areas of affection in nose, the causes were classified into 6 groups: 1. Diseases of External nose-35 pts (6\%), 2. Conditions affecting nasal septum-10pts (26\%), 3. Infections \& Inflammations of nose \& PNS- 210 pts, 4 . Tumors of nose/nasopharynx/PNS-13pts (2\%), 5. Combined 2+3-158pts (25\%) \& 6. Others- 50pts (8\%). Infections \& Inflammations of Nose \& PNS topped the list with $33 \%$ input most commonly come across in this study. Diseases of external nose includes- Cleft lip/palate, Furunculosis/Vestibulitis, Facial cellulitis, Facial trauma with \# Nasal bone \& external nose deformity, Rhinoscleroma, Rhinophyma. No cases of the latter two have been come across so far in the OPD. Conditions affecting nasal septum includes- DNS, Septal abscess, Septal haematoma, Septal perforation. Infections/ Inflammations of Nose \& PNS- Rhinitis, Rhinosinusistis, Polyps, ITH, Nasal mass etc \& Others- postoperative nasal synechiae, Adenoid hypertrophy.

According to aetiology behind occurrence of nasal obstruction, they have been assembled into 8 groups: Developmental-143pts (23\%), Traumatic-106pts (17\%), Hereditary-69pts (11\%), Habitual (nose picking \& recurrent clearing of nose due to regular URI)-10pts (2\%), Inflammatory-227pts, Neoplastic-13 pts (2\%), Iatrogenic-12pts $(2 \%)$, Others-46pts $(7 \%)$. The main root cause which topped the list for nasal obstruction with terms to aetiology is Inflammatory with $36 \%$ contribution that came across in the study.

Along with nasal obstruction as the Primary symptom during presentation during OPD visit, there were around 21 other symptoms as Secondary \& Associated for all nasal pathology. Based on which, both region of involvement as well as symptoms as such were gathered down. Among all the symptoms, Rhinorrhoea topped the list of most common accompanying symptom mainly as Secondary symptom and was seen in 132pts (21\%), while Headache in 107 pts (17\%), h/o recurrent URI along with Mouth breathing/ Halitosis \& Snoring were seen in 59pts (9\%) which ranked second and third in the list of symptom presentation. While, distribution of accompanying symptoms with nasal block in all pts were somewhat evenly dispersed with no particular inclination as such.

While coming over to the region involvement in terms with clinical presentation, but obvious Nose is most common system among the other two to involve in 481pts (77\%). While 39pts (6\%) in Ear \& 106pts (17\%) in Throat \& Other region of involvement.

\section{Conclusion}

This study is one of a kind with numerous, exclusive conclusions are drawn:

a) Mechanical group > Mucosal group in terms of cause for nasal obstruction, which is DNS; seen in nearly $50 \%$ (i.e 299pts).

b) Based on Age distribution, the ratio for (Children: Adult) is nearly $1: 6$.

c) As per Gender predilection, the ratio for (Males: Females) is nearly $1: 2$.

d) According to Chronicity of conditions, the ratio for (Acute: Chronic) is $1: 4$.

e) While the Laterality of involvement of the nasal conditions showed a ratio of (U/L: B/L is nearly 1:4).

f) $39 \%$ (i.e 245 pts) had Mechanical causes for nasal obstruction based on level of obstruction.

g) Based on areas of affection in nose, Infections \& Inflammations of Nose \& PNS listed with 33\% (i.e210pts).

h) As per aetiology of occurrence of all the conditions causing nasal obstruction, inflammatory diseases fall with 36\% (i.e227 pts).

i) Rhinorrhoea was seen as the most common accompanying Secondary symptom in 21\% (i.e 132 pts).

j) According to region involvement in terms with clinical presentation, but obviously Nose is most common system in 481 pts $(77 \%)$.

The purpose of this study is to also bring into light which was somewhere out of focus \& dusted amidst other priorities are3 simple \& must essentials that are needed to lead a healthy living which is being hindered. Those 3 basic amenities needed are Air to 
respire, Aroma to make food tastier\& palatable and calm \&peaceful Nap. All of them are crucial for a strong body and mind. Hence, nasal obstruction should be simply not neglected but must be sorted at the earliest for a well-being.

\section{References}

1. Kara M, Erdoğan H, Güçlü O (2016) Evaluation of sleep quality in patients with nasal septal deviation via the Pittsburgh Sleep Quality Index. J Craniofac Surg 27(7): 1738-1740.

2. Pawankar R (2003) Nasal polyposis: an update: editorial review. Curr Opin Allergy ClinImmunol 3(1): 1-6.

3. Teichgraeber JF, Gruber RP, Tanna N (2016) Surgical management of nasal airway obstruction. Clin Plast Surg 43(1): 41-46.

4. Fraser L, Kelly G (2009) An evidence-based approach to the management of the adult with nasal obstruction. Clin Otolaryngol 34(2): 151-155.

5. Mygind N, Dahl R, Bachert C (2000) Nasal polyposis, eosinophil dominated inflammation, and allergy. Thorax 55(Suppl 2): S79-S83.

6. Chandra RK, Patadia MO, Raviv J (2009) Diagnosis of nasal airway obstruction. Otolaryngol Clin N Am 42(2): 207-225.

7. Bachert C, Gevaert P, Holtappels G (2002) Mediators in nasal polyposis. Curr Allergy Asthma Rep 2(6): 481-487.

8. Udaka T, Suzuki H, Fujimura T (2007) Chronic nasal obstruction causes daytime sleepiness and decreased quality of life even in the absence of snoring. Am J Rhinol 21(5): 564-569.

9. Corey JP, Houser SM, Ng BA (2000) Nasal congestion: a review of its etiology, evaluation, and treatment. Ear Nose Throat J 79(9): 690-698.

10. Staevska MT, Baraniuk JN (2007) Differential diagnosis of persistent non allergic rhinitis and rhinosinusitis syndromes. Clin Allergy Immunol 19: 35-53.

11. Moore GF, Freeman T], Ogren FP (1985) Extended follow-up of total inferior turbinate resection for relief of chronic nasal obstruction. Laryngoscope. 95(9 1): 1095-1099.

12. Farmer SE, Eccles R (2006) Chronic inferior turbinate enlargement and the implications for surgical intervention. Rhinology 44(4): 234-238.

13. Emanuel IA, Shah SB (2000) Chronic rhinosinusitis: allergy and sinus computed tomography relationships. Otolaryngol Head Neck Surg 123(6): 687-691.
14. Ciprandi G, Cirillo I, Vizzaccaro A (2004) Nasal obstruction in patients with seasonal allergic rhinitis: relationships between allergic inflammation and nasal airflow. Int Arch Allergy Immunol 134(1): 3440.

15. Wright ED, Pearl AJ, Manoukian JJ (1998) Laterally hypertrophic adenoids as a contributing factor in otitis media. Int J Pediatr Otorhinolaryngol 45(3): 207-214.

16. Fokkens W, Lund V, Bachert C (2005) EAACI position paper on rhinosinusitis and nasal polyps executive summary. Allergy 60(5): 583601.

17. Berger G, Kattan A, Bernheim J (2000) Acute sinusitis: a histopathological and immunohistochemical study. Laryngoscope 110(12): 2089-2094.

18. Cole P, Chaban R, Naito K (1988) The obstructive nasal septum. Effect of simulated deviations on nasal airflow resistance. Arch Otolaryngol Head Neck Surg 114(4): 410-412.

19. Meltzer EO, Hamilos DL, Hadley JA (2004) Rhinosinusitis: establishing definitions for clinical research and patient care. Otolaryngol Head Neck Surg 131(6 Suppl): S1-S62.

20. Bachert C, Gevaert P, Holtappels G (2000) Nasal polyposis: from cytokines to growth. Am J Rhinol 14(5): 279-290.

21. Berrettini S, Carabelli A, Sellari-Franceschini S (1999) Perennial allergic rhinitis and chronic sinusitis: correlation with rhinologic risk factors. Allergy 54(3): 242-248.

22. Kaliner MA, Osguthorpe JD, Fireman P (1997) Sinusitis: bench to bedside. Current findings, future directions. Otolaryngol Head Neck Surg 116(6 Pt 2): S1-S20.

23. Wang DY, Raza MT, Gordon BR (2004) Control of nasal obstruction in perennial allergic rhinitis. Curr Opin Allergy Clin Immunol 4(3): 165170 .

24. Hedman J, Kaprio J, Poussa T (1999) Prevalence of asthma, aspirin intolerance, nasal polyposis and chronic obstructive pulmonary disease in a population-based study. Int J Epidemiol 28(4): 717-722.

25. Warwick-Brown NP, Marks NJ (1987) Turbinate surgery: how effective is it? A long-term assessment. ORL J Otorhinolaryngol Relat Spec 49(6): 314-320. 